\title{
Effects of thymosin $\beta 4$ on a rat model of severe acute pancreatitis
}

\author{
XIAOBO HE, JIA YU, WENYI GUO, TENG ZUO, QIAO SHI, KAILIANG ZHAO and WEIXING WANG
}

Department of General Surgery, Renmin Hospital of Wuhan University, Wuhan, Hubei 430060, P.R. China

Received September 28, 2014; Accepted August 10, 2015

DOI: 10.3892/etm.2015.2798

\begin{abstract}
The aim of the present study was to investigate the effects of thymosin $\beta 4$ on a rat model of severe acute pancreatitis (SAP) induced by sodium taurocholate (STC) and the underlying mechanism. SAP was induced by the retrograde infusion of $5 \%$ STC $(1 \mathrm{ml} / \mathrm{kg})$ into the bile-pancreatic duct. In certain rats, thymosin $\beta 4(30 \mathrm{mg} / \mathrm{kg})$ was administered intraperitoneally $30 \mathrm{~min}$ prior to the infusion of STC. The severity of pancreatitis was evaluated by the measurement of serum amylase, lipase, tumor necrosis factor- $\alpha$, interleukin (IL)-1 $\beta$, IL-6 and myeloperoxidase (MPO) levels, and histological grading. Nuclear factor (NF)- $\kappa \mathrm{B}$ activation was evaluated by immunohistochemistry and western blot analysis. Intercellular adhesion molecule (ICAM)-1 protein expression in the pancreas was studied using western blot analysis. Prophylactic administration of thymosin $\beta 4$ was found to attenuate serum amylase and lipase activity and the serum concentrations of proinflammatory cytokines. In addition, it attenuated pathological pancreatic injury, pancreatic MPO activity, and the activation of NF- $\kappa \mathrm{B}$ and ICAM-1 in the pancreas. These results suggest that thymosin $\beta 4$ exerts a protective effect against STC-induced pancreatic injury.
\end{abstract}

\section{Introduction}

Acute pancreatitis is an inflammatory disease of the pancreas characterized by acute abdominal pain and increased concentrations of serum amylase and lipase. In the majority of cases, it runs a mild course without complications. However, $\sim 25 \%$ patients develop severe acute pancreatitis (SAP), which may result in systemic inflammatory response syndrome and subsequent multiple organ dysfunction syndrome, and the mortality rate is up to $40 \%(1,2)$. In recent years, many investigators have attempted to reveal the pathogenesis of acute pancreatitis; however, the exact mechanisms are not well understood. Accumulating evidence indicates that SAP

Correspondence to: Professor Weixing Wang, Department of General Surgery, Renmin Hospital of Wuhan University, 238 Jiefang Road, Wuhan, Hubei 430060, P.R. China

E-mail: sate.1lite@163.com

Key words: thymosin $\beta 4$, acute pancreatitis, inflammation, cytokine, neutrophil infiltration is closely associated with tissue injury and microcirculation disorders resulting from the production of proinflammatory cytokines and mediators, including tumor necrosis factor (TNF)- $\alpha$, interleukin (IL)-1 $\beta$, IL-6 and intercellular adhesion molecule (ICAM)-1 (3,4). In addition, studies have shown that acute pancreatitis can lead to activation of the nuclear factor (NF) $-\kappa B$ signaling pathway $(5,6)$. Therefore, reducing the levels of proinflammatory cytokines and adhesion molecules to block the inflammatory cascade may be a valid treatment strategy for acute pancreatitis.

Thymosin $\beta 4$ is a highly conserved polypeptide that was originally isolated from bovine thymus gland extract in 1981 (7). Thymosin $\beta 4$ contains 43-amino acid residues with a molecular weight of $4964.5 \mathrm{Da}$ and an isoelectric point of 4.6 (8). It is widely distributed in many tissues and cell types and is found in high concentrations in blood platelets, macrophages and white blood cells, but not in red blood cells (9). The most prominent physiological role of thymosin $\beta 4$ as the major actin-sequestering peptide contributes to the regulation of actin polymerization in mammalian nucleated cells (10). There is growing evidence that thymosin $\beta 4$ has numerous biological functions in addition to actin binding and sequestration. It has been shown to downregulate a number of key inflammatory mediators (e.g., IL-1 $\beta$ and TNF- $\alpha$ ) and decreases the infiltration of inflammatory cells (11-14). Thymosin $\beta 4$ has also been found to reduce inflammation by inhibiting the activation of $\mathrm{NF}-\kappa \mathrm{B}$ in TNF- $\alpha$-induced cells $(15,16)$. A number of studies have suggested that thymosin $\beta 4$ is capable of promoting new blood vessel formation via stimulating the differentiation and directional migration of endothelial cells $(17,18)$. These activities of thymosin $\beta 4$ play an important role in dermal and corneal wound healing and in recovery from acute myocardial infarction and traumatic brain injury (11,19-21).

However, whether thymosin $\beta 4$ is effective in alleviating inflammatory response and pancreatic tissue injury in SAP has not yet been elucidated. The present study investigated the effect of thymosin $\beta 4$ on pancreatic injury following SAP, to identify whether it could be a good candidate for attenuating the severity of SAP.

\section{Materials and methods}

Animals. Adult male SPF Sprague-Dawley rats (weight, 200-250 g) were obtained from the Center for Animal Experiments of Wuhan University (Wuhan, China). All rats were housed in an animal care facility with a $12 \mathrm{~h}$ light/dark cycle and fed with standard commercial diets and water 
ad libitum. Experimental procedures were approved by the ethics committee of Wuhan University and performed in accordance with the principles of the 1983 Declaration of Helsinki.

Rat model of SAP. Rats were fasted for $12 \mathrm{~h}$ prior to the experiment, but had free access to water. All rats were subjected to the induction of anesthesia in a closed chamber with $4 \%$ isoflurane (Abbott Laboratories, Shanghai, China) in 21 /min oxygen, and were maintained under anesthesia for surgery with $2 \%$ isoflurane in $2 \mathrm{l} / \mathrm{min}$ oxygen. The SAP rat model was elicited by a standardized retrograde infusion of $1 \mathrm{ml} / \mathrm{kg}$ body weight $5 \%$ sodium taurocholate (STC) solution (Sigma-Aldrich, St. Louis, MO, USA) into the bile-pancreatic duct. Saline $(20 \mathrm{ml} / \mathrm{kg})$ was injected into the back subcutaneously to compensate for the fluid loss following the surgery.

Experimental design. The rats were randomly divided into three groups as follows: i) STC + thymosin $\beta 4$ group (T $\beta 4$ group, $n=24$ ). Thymosin $\beta 4$ (GL Biochem Ltd., Shanghai, China; $30 \mathrm{mg} / \mathrm{kg}$ ) was dissolved in saline at a concentration of $3 \mathrm{mg} / \mathrm{ml}$ and was administered intraperitoneally $30 \mathrm{~min}$ prior to STC infusion. ii) STC + saline (SAP group, $n=24$ ). Prior to the induction of SAP, rats in this group received saline by intraperitoneal injection. iii) Sham-operated group (SO group, $\mathrm{n}=24$ ). In this group, rats were treated with sham surgery (the pancreas and duodenum were flipped a number of times) instead of STC infusion. Similar doses of thymosin $\beta 4$ have been demonstrated to exert neuroprotective and neurorestorative effects in experimental models of traumatic brain injury (22).

Rats in the three groups were sacrificed at 3,6 and $12 \mathrm{~h}$ after treatment ( $n=8$ per group at each time-point). Blood samples were collected by intracardiac puncture at the respective time-points in the three groups. Samples were centrifuged at $3,000 \mathrm{x} \mathrm{g}$ for $15 \mathrm{~min}$, and the serum was stored at $-20^{\circ} \mathrm{C}$ for subsequent biochemical and cytokine measurements. Following sacrifice, tissue from the head of the pancreas was harvested and fixed in $4 \%$ phosphate-buffered formaldehyde for histopathological observation. The remaining part of the pancreas was snap frozen in liquid nitrogen and stored at $-80^{\circ} \mathrm{C}$ for assay.

Histopathological examination. For histological analysis, paraffin-embedded pancreatic tissues were sliced to a thickness of $4 \mu \mathrm{m}$ and stained with hematoxylin and eosin (H\&E). The morphology of the pancreatic tissues was evaluated and documented by two experienced pathologists who were blinded to the experiment. Pancreatic histological assessment was scored for the severity of pancreatitis based on edema, inflammatory cell infiltrate and hemorrhage, and acinar necrosis according to the scale described by Schmidt et al (23).

Serum amylase (AMY) and lipase (LIP) assays. Serum AMY and LIP levels were measured using standard techniques with a fully automatic chemistry analyzer (Olympus AU2700 Chemistry-Immuno Analyzer; Olympus Inc., Tokyo, Japan).

Measurement of inflammatory mediators and cytokines. The serum concentrations of TNF- $\alpha$, IL- $1 \beta$ and IL- 6 were measured in units of $\mathrm{pg} / \mathrm{ml}$ by the use of commercially available enzyme-linked immunosorbent assay (ELISA) kits (eBioscience Ltd., Vienna, Austria). The absorbance was read by an automated microplate ELISA reader (Bio-Rad Laboratories, Inc., Hercules, CA, USA) and concentrations were calculated by the standard curve run on each assay plate. All samples were measured in duplicate.

Myeloperoxidase (MPO) determination. Neutrophil infiltration in the pancreas was quantitated by MPO activity. MPO activity was measured photometrically with 3,3',5,5'-tetramethylbenzidine as a substrate, and the reaction was initiated by adding hydrogen peroxide to the medium. The MPO activity assay was performed with a commercial kit according to the manufacturer's instructions (Nanjing Jiancheng Bioengineering Institute, Nanjing, China).

Immunohistochemistry assay. Pancreatic tissue sections were obtained from paraffin-embedded tissues. Sections of $4 \mu \mathrm{m}$ thickness were deparaffinized with xylene, and $0.3 \%$ hydrogen peroxide was used to inactivate endogenous peroxidase activity. Sections were incubated in 5\% normal goat serum diluted in phosphate-buffered saline (PBS). Endogenous biotin and avidin binding sites were blocked by avidin and biotin, respectively. The sections were incubated overnight with rabbit polyclonal anti-rat NF-кB p65 antibody (1:100; C22B4; Cell Signaling Technology, Inc., Danvers, MA, USA) in a humidity chamber at $4^{\circ} \mathrm{C}$, then counterstained with hematoxylin. Negative control experiments were performed in which PBS was used instead of primary antibody.

Western blot analysis. Pancreatic NF- $\kappa \mathrm{B}$ p65, I- $\kappa \mathrm{B} \alpha$ and ICAM-1 levels at $12 \mathrm{~h}$ after STC infusion were determined by Western blot analysis. Cytoplasmic and nuclear proteins were extracted using the Nuclear-Cytosol Extraction kit (Applygen Technologies Inc., Beijing, China). Concentrations of protein in the samples were evaluated by the Bradford method with bovine serum albumin as a standard. Equal amounts of protein samples were electrophoresed using $8 \%$ sodium dodecyl sulfate polyacrylamide gel electrophoresis (SDS-PAGE) and then transferred to nitrocellulose membranes. Non-specific binding was blocked with 5\% skimmed milk in Tris-buffered saline and $0.1 \%$ Tween 20 (TBST) buffer at room temperature for $2 \mathrm{~h}$. The cytoplasmic proteins were incubated with primary antibodies of rabbit polyclonal anti-rat inhibitor of $\kappa \mathrm{B}(\mathrm{I}-\kappa \mathrm{B}) \alpha$ antibody (1:1,000; sc-371; Santa Cruz Biotechnology, Inc., Dallas, TX, USA), actin antibody (1:2,000; sc-130656; Santa Cruz Biotechnology, Inc.) and ICAM-1 antibody (1:1,000; sc-7891; Santa Cruz Biotechnology, Inc.). In addition, the nuclear proteins were incubated with rabbit polyclonal anti-rat NF-kB p65 (1:1,000; C22B4; Cell Signaling Technology, Inc.) and histone H3 antibody (1:1,000; sc-10809; Santa Cruz Biotechnology, Inc.) overnight at $4^{\circ} \mathrm{C}$. Following extensive rinsing with TBST, the blots were incubated with horseradish peroxidase-conjugated goat anti-rabbit secondary antibody (1:5,000; Pierce Biotechnology, Rockford, IL, USA) for $1 \mathrm{~h}$ at room temperature, and developed with the use of an electrochemiluminescent reagent (Immobilon Western HRP Substrate; EMD Millipore, Bedford, MA, USA) and images 
A

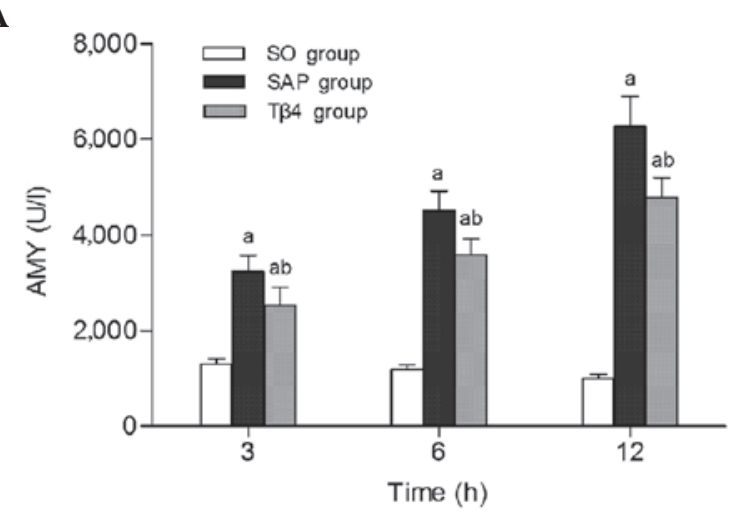

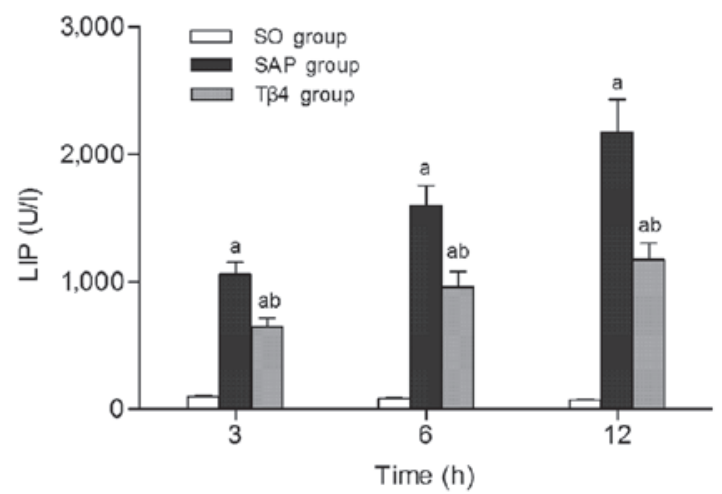

Figure 1. Serum levels of (A) amylase (AMY) and (B) lipase (LIP). Thymosin $\beta 4$ (T $\beta 4)$ significantly reduced the increase of AMY and LIP levels in rats with severe acute pancreatitis (SAP). Results are expressed as mean \pm standard deviation ( $\mathrm{n}=8$ rats per group). ${ }^{\text {a }}<0.05$ vs. the sham-operated (SO) group at the same time-point, ${ }^{\mathrm{b}} \mathrm{P}<0.05$ vs. the SAP group at the same time-point.
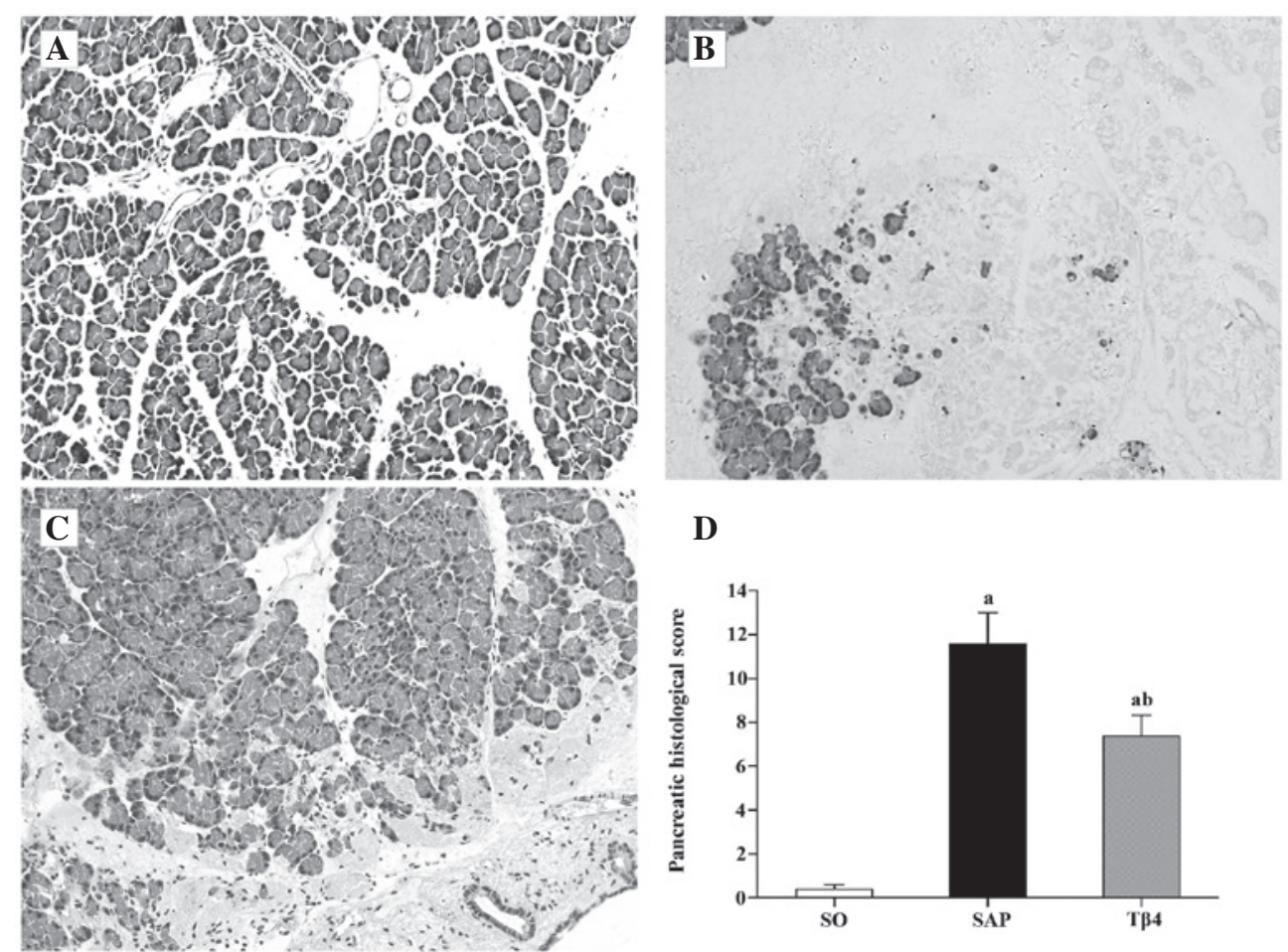

D

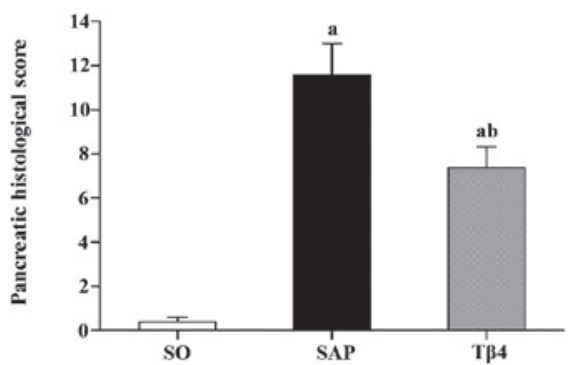

Figure 2. Morphologic changes of the pancreas at $12 \mathrm{~h}$ after pancreatitis. Representative hematoxylin and eosin-stained sections were examined by light microscopy (original magnification, x200). (A) No histological alterations were observed in the pancreatic tissues from the sham-operated (SO) rats. The histological signs of pancreatic injury in (B) the severe acute pancreatitis (SAP) group were significantly reduced in extent and severity by (C) pretreatment with thymosin $\beta 4$ (T $\beta 4$ ). (D) Comparison of the total pathological scores of the pancreas in the three groups. Results are expressed as mean \pm standard deviation ( $\mathrm{n}=8$ rats per group). ${ }^{\mathrm{P}} \mathrm{P}<0.05$ vs. the $\mathrm{SO}$ group, ${ }^{\mathrm{b}} \mathrm{P}<0.05$ vs. the $\mathrm{SAP}$ group.

were captured on light-sensitive imaging film (Kodak, Rochester, NY, USA). The protein bands were quantified by densitometry using Quantity One 4.5.0 software (Bio-Rad Laboratories, Inc., Richmond, CA, USA).

Statistical analysis. Data was analyzed using SPSS statistical software, version 16.0 (SPSS Inc., Chicago, IL, USA). All data are expressed as the mean \pm standard deviation. Data were compared between all groups by one-way analysis of variance (ANOVA). A two-tailed P-value of less than 0.05 was considered statistically significant.

\section{Results}

Analysis of serum AMY and LIP levels. As shown in Fig. 1, the SAP group had significant increased serum AMY and LIP levels from $3 \mathrm{~h}$ to $12 \mathrm{~h}$ compared with those in the SO group $(\mathrm{P}<0.05)$. Compared with the SAP group, treatment with thymosin $\beta 4$ prior to STC infusion significantly reduced the serum levels of AMY and LIP at each time-point $(\mathrm{P}<0.05)$.

Histopathological assay. Representative pathological sections of the pancreatic tissue are shown in Fig. 2A-C. In the SAP 
A

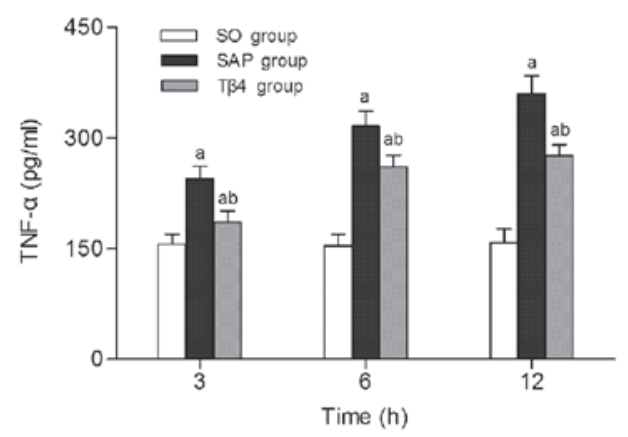

C

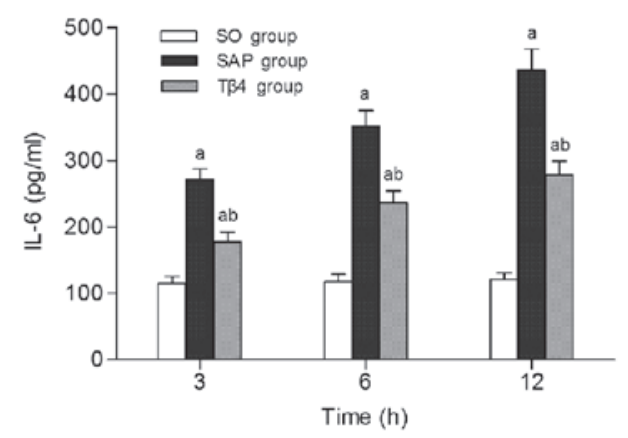

B

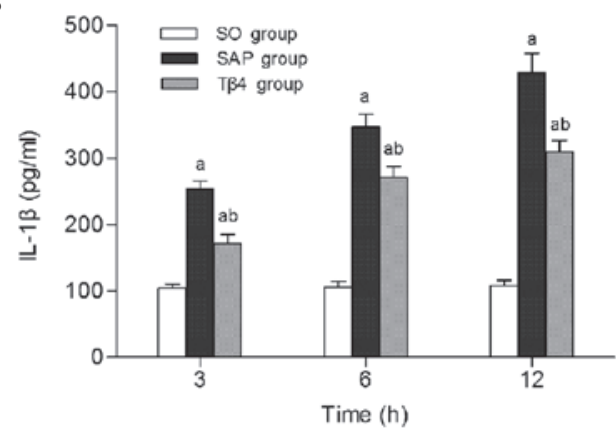

D

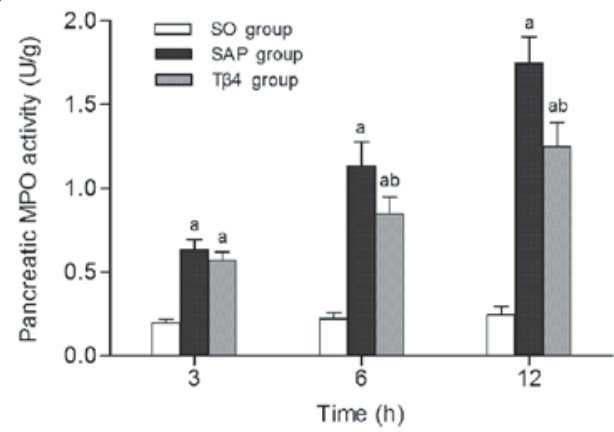

Figure 3. Effects of thymosin $\beta 4$ (T $\beta 4$ ) on proinflammatory cytokine production and pancreatic neutrophil infiltration. Serum levels of (A) tumor necrosis factor (TNF)- $\alpha$, (B) interleukin (IL)-1 $\beta$ and (C) IL- 6 and were quantified by enzyme-linked immunosorbent assay in rats at different times after severe acute pancreatitis (SAP). (D) Treatment with T $\beta 4$ significantly reduced the sodium taurocholate-induced increase of myeloperoxidase (MPO) activity at 6 and $12 \mathrm{~h}$ in the pancreas. Results are expressed as mean \pm standard deviation ( $\mathrm{n}=8$ rats per group). ${ }^{\mathrm{P}}<0.05$ vs. the sham-operated (SO) group at the same time-point, ${ }^{\mathrm{b}} \mathrm{P}<0.05$ vs. the SAP group at the same time-point.

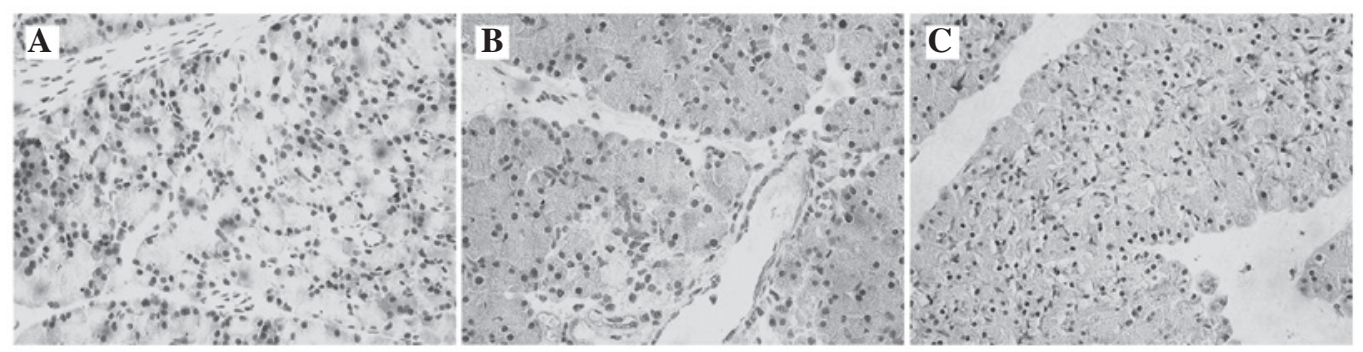

Figure 4. Immunohistochemical localization of nuclear factor (NF)- $\mathrm{B}$ p65 protein in the pancreas in the three groups (original magnification, $\mathrm{x} 400)$. (A) Weak immunoreactivity, mainly in the cytoplasm, was observed in pancreatic sections from a rat from the sham-operated group. (B) Intense immunoreactivity in the nucleus in a rat with severe acute pancreatitis. (C) The intensity of positive NF- $\kappa$ B p65 protein staining in the nucleus was markedly reduced following the administration of thymosin $\beta 4$.

group, massive areas of acinar necrosis accompanied by infiltration of inflammatory cells, vacuolization and hemorrhage were observed. Rats in the SO group showed little morphological evidence of pancreatic injury, with the exception of mild interstitial edema. As shown in Fig. 2D, the pancreatic histological score was significantly decreased in the T $\beta 4$ group compared with the SAP group.

Analysis of serum proinflammatory cytokine levels and pancreatic MPO activity. Serum proinflammatory cytokine levels were analyzed to determine the effect of thymosin $\beta 4$ on the inflammatory process of SAP. As illustrated in Fig. 3A-C, serum concentrations of IL- $1 \beta$, IL- 6 and TNF- $\alpha$ increased continuously with time. However, the increases in the concentrations of these cytokines following SAP were markedly decreased by the administration of thymosin $\beta 4(\mathrm{P}<0.05)$. Neutrophil infiltration in the pancreas was evaluated by the measurement of MPO activity after SAP. The MPO activity of the SAP group increased significantly at each time-point compared with that in the $\mathrm{SO}$ group $(\mathrm{P}<0.05)$. When administered prophylactically, thymosin $\beta 4$ reduced MPO activity in the pancreatic tissue at 6 to $12 \mathrm{~h}$ compared with that in the SAP group ( $\mathrm{P}<0.05$; Fig. 3D).

Immunohistochemical analysis. To investigate the localization of $\mathrm{NF}-\kappa \mathrm{B}$ p65 expression, an immunohistochemical assay was conducted. In the $\mathrm{SO}$ group, $\mathrm{NF}-\kappa \mathrm{B}$ p 65 was expressed mainly in the cytoplasm in pancreatic tissues (Fig. 4A). NF- $\kappa \mathrm{B}$ p65 immunoreactivity was highly expressed in the nucleus following the administration of STC (Fig. 4B). However, a marked reduction in $\mathrm{NF}-\kappa \mathrm{B}$ p65 staining was observed in the cell nuclei with thymosin $\beta 4$ pretreatment, and the staining increased in the cytoplasm (Fig. 4C). 
A

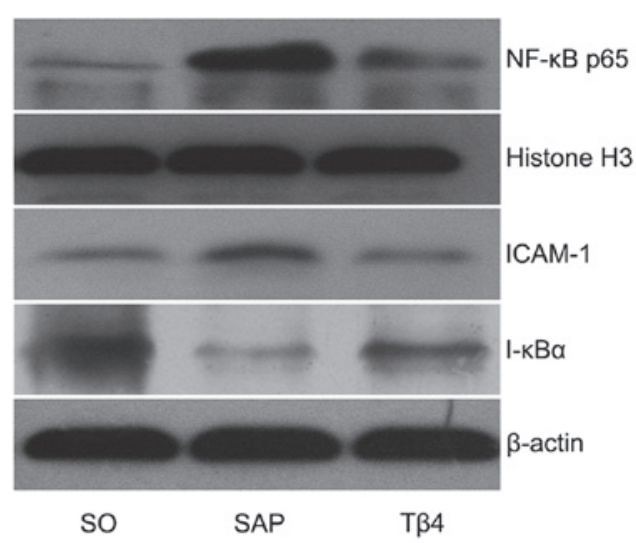

C

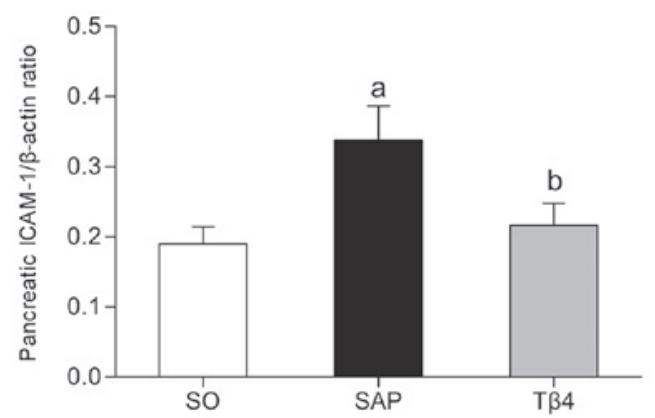

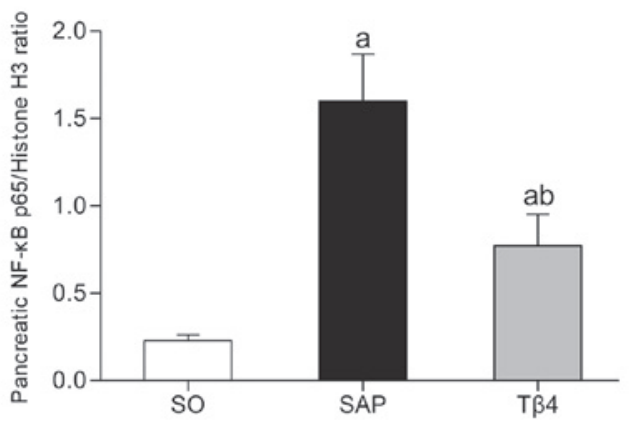

D

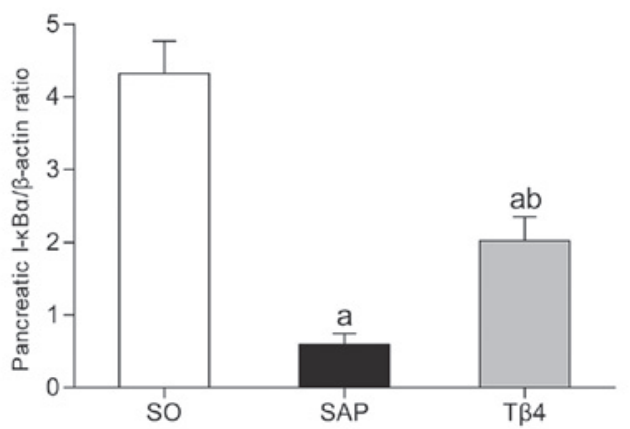

Figure 5. Western blotting to evaluate the activation of nuclear factor (NF)- $\kappa \mathrm{B}$ and intercellular adhesion molecule (ICAM)-1 in pancreatic tissue at $12 \mathrm{~h}$ after pancreatitis. NF- $\kappa$ B p 65 and inhibitor of $\kappa \mathrm{B}(\mathrm{I}-\kappa \mathrm{B}) \alpha$ proteins were measured in pancreatic tissue as indicators of the activation of NF- $\kappa \mathrm{B}$. Sodium taurocholate-induced pancreatitis significantly increased the tissue concentrations of NF- $\mathrm{B}$ p 65 and ICAM-1 proteins compared with those in the sham-operated (SO) group rats. Thymosin $\beta 4$ (T $\beta 4$ ) effectively inhibited the activation of NF- $\kappa$ B and ICAM-1 in the pancreas following severe acute pancreatitis (SAP). (A) Representative image and densitometric analysis of the bands for (B) NF- $\kappa \mathrm{B}$ p65, (C) ICAM-1 and (D) I- $\kappa \mathrm{B} \alpha$ ratios. ${ }^{a} \mathrm{P}<0.05$ vs. the $\mathrm{SO}$ group, ${ }^{\mathrm{b}} \mathrm{P}<0.05 \mathrm{vs}$. the SAP group.

$N F-\kappa B$ p $65, I-\kappa B \alpha$ and ICAM-1 protein expression. Fig. $5 \mathrm{~A}$ and $\mathrm{B}$ shows that the expression of $\mathrm{NF}-\kappa \mathrm{B}$ p 65 protein in the pancreas in the SAP group was higher than that in the $\mathrm{SO}$ group at $12 \mathrm{~h}$. In the $\mathrm{T} \beta 4$ group, the $\mathrm{NF}-\kappa \mathrm{B}$ p 65 protein was expressed at a much lower level than in the SAP group $(\mathrm{P}<0.05)$. Furthermore, the SAP group showed a significant reduction of pancreatic $\mathrm{I}-\kappa \mathrm{B} \alpha$ protein expression (Fig. 5D). As shown in Fig. 5C, the expression of pancreatic ICAM-1 protein in the SAP group was much higher than that in the SO group. However, ICAM-1 protein expression was much lower in the $\mathrm{T} \beta 4$ group than in the SAP group $(\mathrm{P}<0.05)$.

\section{Discussion}

Acute pancreatitis causes a release of various inflammatory mediators, attracts inflammatory cells to the vascular endothelium and induces the expression of adhesion molecules $(1,24)$. Studies have shown that NF- $\kappa \mathrm{B}$ plays a critical role in the development of acute pancreatitis $(25,26)$. Therefore, intervention in $\mathrm{NF}-\kappa \mathrm{B}$ activation can eliminate the induced overexpression of proinflammatory cytokines such as TNF- $\alpha$, IL-1 $\beta$ and IL-6. As reviewed recently, thymosin $\beta 4$ has clear anti-inflammatory and anti-septic shock activities $(12,26)$. In addition, thymosin $\beta 4$ can inhibit TNF- $\alpha$-mediated NF- $\kappa \mathrm{B}$ nuclear translocation and activation $(15,16,27)$.

In the present study, the increased AMY and LIP levels in the SAP group and the elevated histopathological score of the pancreas indicate that pancreatic damage increased gradually following SAP, and that the SAP rat model was successfully induced. The results also demonstrate that the prophylactic administration of thymosin $\beta 4$ alleviated the following: i) serum AMY and LIP levels; ii) pancreatic neutrophil infiltration; iii) pancreatic damage; iv) proinflammatory cytokine production; and $\mathrm{v}$ ) activation of $\mathrm{NF}-\kappa \mathrm{B}$ and ICAM-1. These results indicate that pretreatment with thymosin $\beta 4$ ameliorates the degree of SAP and exerts potent anti-inflammatory effects in rats.

Thymosin $\beta 4$ has shown promising efficacy in animal models of various diseases, such as myocardial infarction, dermal wounds, multiple sclerosis, sepsis and endotoxic shock $(12,20,28-31)$. However, to the best of our knowledge, there have been no reports concerning thymosin $\beta 4$ in the treatment of acute pancreatitis until now. The anti-inflammatory effect of thymosin $\beta 4$ may be due to the inhibition of proinflammatory transcription factors such as NF- $\kappa \mathrm{B}$. Therefore, the present study was conducted to investigate the alleviating effect of thymosin $\beta 4$ on pancreatic injury associated with SAP.

Previous studies have shown that the active RelA/p65 $\mathrm{NF}-\kappa \mathrm{B}$ subunit plays a critical role in the systemic inflammatory response in acute pancreatitis $(32,33)$. NF- $\kappa \mathrm{B}$ is normally inactive and resides in the cytoplasm, where it is sequestered by $\mathrm{I}-\kappa \mathrm{B}$ (34). Upon stimulation, I- $\kappa \mathrm{B}$ kinase rapidly phosphorylates $\mathrm{I}-\kappa \mathrm{B}$ proteins, which leads to their degradation 
and the release of active NF- $\kappa \mathrm{B}$. The released $\mathrm{NF}-\kappa \mathrm{B}$ translocates to the nucleus and activates the transcription of several important proinflammatory genes: TNF- $\alpha$, IL-1 $\beta$, IL-6 and ICAM-1 $(35,36)$. Inflammatory cytokines such as TNF- $\alpha$, IL-1 $\beta$ and IL- 6 play an important role in the early stage of acute pancreatitis and affect the outcome of the disease; in particular, they are thought to be a trigger of cascading inflammatory response and multiple organ failure in SAP (37-39). In the present study, the results also revealed an increase in the levels of these inflammatory cytokines after acute pancreatitis. Prophylactic administration of thymosin $\beta 4$ markedly reduced their serum levels in rats. This illustrated that thymosin $\beta 4$ is able to attenuate the inflammatory response in SAP. The results of immunohistochemistry detection indicated that $\mathrm{NF}-\kappa \mathrm{B}$ translocated from the cytoplasm into the nucleus in the pancreatic tissues upon activation during pancreatitis. Western blotting results demonstrated that the $\mathrm{I}-\kappa \mathrm{B} \alpha$ protein expression levels were reduced during pancreatitis, and that pretreatment with thymosin $\beta 4$ inhibited the degradation of $\mathrm{I}-\kappa \mathrm{B} \alpha$. These results demonstrate that thymosin $\beta 4$ can inhibit $\mathrm{NF}-\kappa \mathrm{B}$ activation and attenuate pancreatic injury.

The infiltration of inflammatory cells into the pancreas is an early and central event in acute pancreatitis that promotes local damage and systemic complications (40). Studies have demonstrated that the sequestration of neutrophils plays a key role in the development of pancreatitis (41). Adhesion molecules such as ICAM-1 are upregulated in acute pancreatitis, and cause deleterious effects via neutrophil recruitment to the pancreas (42). For the optimum analysis of ICAM-1 activation, measurements were taken at the $12 \mathrm{~h}$ time-point, which coincides with the peak in serum cytokine levels. The results revealed that the expression of ICAM-1 was significantly increased in pancreatic tissue following STC infusion, and pretreatment with thymosin $\beta 4$ markedly reduced the expression of ICAM-1 protein in the pancreas.

The increase of ICAM-1 expression in the pancreas correlated with an increase of leukocyte infiltration measured by MPO activity. MPO is a peroxidase enzyme produced by azurophilic granules in neutrophils, which has been used as a biomarker for neutrophil infiltration in studies of acute pancreatitis $(42,43)$. In addition, MPO activity can reflect the severity of inflammation (43). MPO activity noticeably increased with the induction of pancreatitis, and the increase of pancreatic MPO activity indicated the progressive aggravation of pancreatic injury. The thymosin $\beta 4$ treatment markedly reduced the increase in pancreatic MPO activity at 6 to $12 \mathrm{~h}$ after acute pancreatitis, which suggests a significant reduction in neutrophil infiltration into the pancreatic tissues. The finding that thymosin $\beta 4$ markedly reduced neutrophil infiltration is consistent with a previous report demonstrating that treatment with anti-ICAM-1 antibody decreased leukocyte infiltration in pancreas and attenuated tissue damage (44).

In summary, the present study demonstrates that thymosin $\beta 4$ attenuates the severity of pancreatic injury in acute pancreatitis, through inhibiting $\mathrm{NF}-\kappa \mathrm{B}$ activation and reducing the formation of proinflammatory cytokines (TNF- $\alpha$, IL-1 $\beta$ and IL-6) and decreasing the expression of the adhesion molecule ICAM-1 and neutrophil infiltration. However, there are a number of limitations to this study. For example, the protective effect associated with thymosin $\beta 4$ was not investigated in depth, and mechanism by which thymosin $\beta 4$ inhibited the $\mathrm{NF}-\kappa \mathrm{B}$ signal pathway remains unclear. The present results may serve as a basis for further studies on the therapeutic potential of thymosin $\beta 4$ in SAP.

\section{Acknowledgements}

The authors thank the Key Laboratory of Hubei Province for Digestive System Disease, Renmin Hospital of Wuhan University. This study was supported by the Major Scientific Research Projects of Health Department of Hubei Province (No. JX6A07), and the National Natural Science Foundation of China (No. 81300356 and No. 81370562).

\section{References}

1. Bhatia M, Brady M, Shokuhi S, Christmas S, Neoptolemos JP and Slavin J: Inflammatory mediators in acute pancreatitis. J Pathol 190: 117-125, 2000.

2. Mofidi R, Duff MD, Wigmore SJ, Madhavan KK, Garden OJ and Parks RW: Association between early systemic inflammatory response, severity of multiorgan dysfunction and death in acute pancreatitis. Br J Surg 93: 738-744, 2006.

3. Granger J and Remick D: Acute pancreatitis: Models, markers and mediators. Shock 24: 45-51, 2005.

4. Papachristou GI, Clermont G, Sharma A, Yadav D and Whitcomb DC: Risk and markers of severe acute pancreatitis. Gastroenterol Clin North Am 36: 277-296, 2007.

5. Yu J, Deng W, Wang W, Ding Y, Jin H, Chen C, Chen X, Xiong X and Xu S: Inhibition of poly (ADP-ribose) polymerase attenuates acute kidney injury in sodium taurocholate-induced acute pancreatitis in rats. Pancreas 41: 1299-1305, 2012.

6. Rakonczay Z Jr, Hegyi P, Takács T, McCarroll J and Saluja AK: The role of NF-kappaB activation in the pathogenesis of acute pancreatitis. Gut 57: 259-267, 2008.

7. Low TL, Hu SK and Goldstein AL: Complete amino acid sequence of bovine thymosin beta 4: A thymic hormone that induces terminal deoxynucleotidyl transferase activity in thymocyte populations. Proc Natl Acad Sci USA 78: 1162-1166, 1981.

8. Hannappel E: Thymosin beta4 and its posttranslational modifications. Ann N Y Acad Sci 1194: 27-35, 2010.

9. Hannappel E and van Kampen M: Determination of thymosin beta 4 in human blood cells and serum. J Chromatogr 397: 279-285, 1987.

10. Goldstein AL, Hannappel E and Kleinman HK: Thymosin beta4: Actin-sequestering protein moonlights to repair injured tissues. Trends Mol Med 11: 421-429, 2005.

11. Sosne G, Chan CC, Thai K, Kennedy M, Szliter EA, Hazlett LD and Kleinman HK: Thymosin beta 4 promotes corneal wound healing and modulates inflammatory mediators in vivo. Exp Eye Res 72: 605-608, 2001.

12. Badamchian M, Fagarasan MO, Danner RL, Suffredini AF, Damavandy $\mathrm{H}$ and Goldstein AL: Thymosin beta (4) reduces lethality and down-regulates inflammatory mediators in endotoxin-induced septic shock. Int Immunopharmacol 3: 1225-1233, 2003.

13. Sosne G, Christopherson PL, Barrett RP and Fridman R: Thymosin-beta4 modulates corneal matrix metalloproteinase levels and polymorphonuclear cell infiltration after alkali injury. Invest Ophthalmol Vis Sci 46: 2388-2395, 2005.

14. Sosne G, Szliter EA, Barrett R, Kernacki KA, Kleinman H and Hazlett LD: Thymosin beta 4 promotes corneal wound healing and decreases inflammation in vivo following alkali injury. Exp Eye Res 74: 293-299, 2002.

15. Sosne G, Qiu P, Christopherson PL and Wheater MK: Thymosin beta 4 suppression of corneal NFkappaB: A potential anti-inflammatory pathway. Exp Eye Res 84: 663-669, 2007.

16. Qiu P, Wheater MK, Qiu Y and Sosne G: Thymosin beta4 inhibits TNF-alpha-induced NF-kappaB activation, IL-8 expression and the sensitizing effects by its partners PINCH-1 and ILK. FASEB J 25: 1815-1826, 2011.

17. Malinda KM, Goldstein AL and Kleinman HK: Thymosin beta 4 stimulates directional migration of human umbilical vein endothelial cells. FASEB J 11: 474-481, 1997. 
18. Grant DS, Rose W, Yaen C, Goldstein A, Martinez J and Kleinman H: Thymosin beta4 enhances endothelial cell differentiation and angiogenesis. Angiogenesis 3: 125-135, 1999.

19. Treadwell T, Kleinman HK, Crockford D, Hardy MA, Guarnera GT and Goldstein AL: The regenerative peptide thymosin $\beta 4$ accelerates the rate of dermal healing in preclinical animal models and in patients. Ann N Y Acad Sci 1270: 37-44, 2012.

20. Crockford D: Development of thymosin beta4 for treatment of patients with ischemic heart disease. Ann NY Acad Sci 1112: 385-395, 2007.

21. Xiong Y, Mahmood A, Meng Y, Zhang Y, Zhang ZG, Morris DC and Chopp M: Treatment of traumatic brain injury with thymosin $\beta_{4}$ in rats. J Neurosurg 114: 102-115, 2011.

22. Xiong Y, Zhang Y, Mahmood A, Meng Y, Zhang ZG, Morris DC and Chopp M: Neuroprotective and neurorestorative effects of thymosin $\beta 4$ treatment initiated $6 \mathrm{~h}$ after traumatic brain injury in rats. J Neurosurg 116: 1081-1092, 2012.

23. Schmidt J, Rattner DW, Lewandrowski K, Compton CC, Mandavilli U, Knoefel WT and Warshaw AL: A better model of acute pancreatitis for evaluating therapy. Ann Surg 215: 44-56, 1992

24. Nakae H, Endo S, Sato N, Wakabayashi G, Inada K and Sato S: Involvement of soluble adhesion molecules in acute pancreatitis Eur Surg Res 33: 377-382, 2001.

25. Sah RP, Dawra RK and Saluja AK: New insights into the pathogenesis of pancreatitis. Curr Opin Gastroenterol 29: 523-530, 2013

26. Girardi M, Sherling MA, Filler RB, Shires J, Theodoridis E, Hayday AC and Tigelaar RE: Anti-inflammatory effects in the skin of thymosin-beta4 splice-variants. Immunology 109: 1-7, 2003.

27. Hinkel R, Trenkwalder T and Kupatt C: Molecular and cellular mechanisms of thymosin $\beta 4$-mediated cardioprotection. Ann NY Acad Sci 1269: 102-109, 2012.

28. Bock-Marquette I, Saxena A, White MD, Dimaio JM and Srivastava D: Thymosin beta4 activates integrin-linked kinase and promotes cardiac cell migration, survival and cardiac repair Nature 432: 466-472, 2004.

29. Shrivastava S, Srivastava D, Olson EN, DiMaio JM and Bock-Marquette I: Thymosin beta4 and cardiac repair. Ann NY Acad Sci 1194: 87-96, 2010.

30. Philp D, Badamchian M, Scheremeta B, Nguyen M, Goldstein AL and Kleinman HK: Thymosin beta 4 and a synthetic peptide containing its actin-binding domain promote dermal wound repair in $\mathrm{db} / \mathrm{db}$ diabetic mice and in aged mice. Wound Repair Regen 11: 19-24, 2003.

31. Zhang J, Zhang ZG, Morris D, Li Y, Roberts C, Elias SB and Chopp M: Neurological functional recovery after thymosin beta4 treatment in mice with experimental auto encephalomyelitis. Neuroscience 164: 1887-1893, 2009.
32. Chen X, Ji B, Han B, Ernst SA, Simeone D and Logsdon CD: NF-kappaB activation in pancreas induces pancreatic and systemic inflammatory response. Gastroenterology 122: 448-457, 2002.

33. Huang H, Liu Y, Daniluk J, Gaiser S, Chu J, Wang H, Li ZS, Logsdon $\mathrm{CD}$ and $\mathrm{Ji} \mathrm{B}$ : Activation of nuclear factor- $\kappa \mathrm{B}$ in acinar cells increases the severity of pancreatitis in mice. Gastroenterology 144: 202-210, 2013.

34. Baldwin AS Jr: The NF-kappaB and I kappaB proteins: New discoveries and insights. Annu Rev Immunol 14: 649-683, 1996.

35. Kim H, Seo JY, Roh KH, Lim JW and Kim KH: Suppression of NF-kappaB activation and cytokine production by $\mathrm{N}$-acetylcysteine in pancreatic acinar cells. Free Radic Biol Med 29: 674-683, 2000.

36. Telek G, Ducroc R, Scoazec JY, Pasquier C, Feldmann G and Rozé C: Differential upregulation of cellular adhesion molecules at the sites of oxidative stress in experimental acute pancreatitis. J Surg Res 96: 56-67, 2001.

37. Surbatovic M and Radakovic S: Tumor necrosis factor- $\alpha$ levels early in severe acute pancreatitis: Is there predictive value regarding severity and outcome? J Clin Gastroenterol 47: 637-643, 2013

38. Malmstrøm ML, Hansen MB, Andersen AM, Ersbøll AK, Nielsen OH, Jørgensen LN and Novovic S: Cytokines and organ failure in acute pancreatitis: Inflammatory response in acute pancreatitis. Pancreas 41: 271-277, 2012.

39. Makhija R and Kingsnorth AN: Cytokine storm in acute pancreatitis. J Hepatobiliary Pancreat Surg 9: 401-410, 2002.

40. Vonlaufen A, Apte MV, Imhof BA and Frossard JL: The role of inflammatory and parenchymal cells in acute pancreatitis. J Pathol 213: 239-248, 2007.

41. Mota R, Sánchez-Bueno F, Berenguer-Pina JJ, Hernández-Espinosa D, Parrilla $\mathrm{P}$ and Yélamos $\mathrm{J}$ : Therapeutic treatment with poly(ADP-ribose) polymerase inhibitors attenuates the severity of acute pancreatitis and associated liver and lung injury. Br J Pharmacol 151: 998-1005, 2007.

42. Chen C, Xu S, Wang WX, Ding YM, Yu KH, Wang B and Chen XY: Rosiglitazone attenuates the severity of sodium taurocholate-induced acute pancreatitis and pancreatitis-associated lung injury. Arch Med Res 40: 79-88, 2009.

43. Chooklin S, Pereyaslov A and Bihalskyy I: Pathogenic role of myeloperoxidase in acute pancreatitis. Hepatobiliary Pancreat Dis Int 8: 627-631, 2009.

44. Werner J, Z'graggen K, Fernández-del Castillo C, Lewandrowski KB, Compton CC and Warshaw AL: Specific therapy for local and systemic complications of acute pancreatitis with monoclonal antibodies against ICAM-1. Ann Surg 229: 834-842, 1999. 